\title{
Restrictive spirometric pattern and true pulmonary restriction in a general population sample aged 50 - 64 years
}

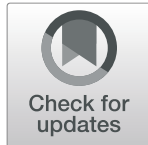

Kjell Torén ${ }^{1,2^{*}}$ D, Linus Schiöler ${ }^{1}$, Jonas Brisman², Andrei Malinovschi ${ }^{3}$, Anna-Carin Olin ${ }^{1,2}$, Göran Bergström ${ }^{4}$ and Björn Bake ${ }^{5}$

\begin{abstract}
Background: There is low diagnostic accuracy of the proxy restrictive spirometric pattern (RSP) to identify true pulmonary restriction. This knowledge is based on patients referred for spirometry and total lung volume determination by plethysmograpy, single breath nitrogen washout technique or gas dilution and selected controls. There is, however, a lack of data from general populations analyzing whether RSP is a valid proxy for true pulmonary restriction. We have validated RSP in relation to true pulmonary restriction in a general population where we have access to measurements of total lung capacity (TLC) and spirometry.

Methods: The data was from the Swedish CArdioPulmonary biolmage Study (SCAPIS Pilot), a general populationbased study, comprising 983 adults aged 50-64. All subjects answered a respiratory questionnaire. Forced expiratory volume in $1 \mathrm{~s}\left(\mathrm{FEV}_{1}\right)$ and forced vital capacity (FVC) were obtained before and after bronchodilation. TLC and residual volume (RV) was recorded using a body plethysmograph. All lung function values are generally expressed as percent predicted (\% predicted) or in relation to lower limits of normal (LLN). True pulmonary restriction was defined as TLC $<L L N_{5}$ defined as a $Z$ score $<-1.645$, i e the fifth percentile. RSP was defined as FEV $/$ /FVC $\geq L L N$ and FVC $<$ LLN after bronchodilation. Specificity, sensitivity, positive and negative likelihood ratios were calculated, and 95\% confidence intervals (Cls) were calculated.
\end{abstract}

Results: The prevalence of true pulmonary restriction was 5.4\%, and the prevalence of RSP was $3.4 \%$. The sensitivity of RSP to identify true pulmonary restriction was $0.34(0.20-0.46)$, the corresponding specificity was 0.98 (0.97-0.99), and the positive likelihood ratio was $21.1(11.3-39.4)$ and the negative likelihood ratio was 0.67 (0.55-0.81).

Conclusions: RSP has low accuracy for identifying true pulmonary restriction. The results support previous observations that RSP is useful for ruling out true pulmonary restriction.

Keywords: Validity, Restrictive lung disease, RSP, TLC, Reference values, SCAPIS

\footnotetext{
* Correspondence: Kjell.Toren@amm.gu.se

'Occupational and Environmental Medicine, School of Public Health and Community Medicine, Sahlgrenska Academy, University of Gothenburg, Box 414, S-405 30 Gothenburg, Sweden

${ }^{2}$ Department of Occupational and Environmental Medicine, Sahlgrenska University Hospital, Gothenburg, Sweden

Full list of author information is available at the end of the article
}

\section{Introduction}

True pulmonary restriction is synonymous with reduced total lung capacity (TLC) and is associated with a number of pathological conditions that either take up space in the thoracic cavity or restricts movements of the thoracic cage or diaphragm - for example interstitial lung diseases, pleurisy, lung edema, kyphosis, neuromuscular weakness and severe obesity. Measurements of TLC

C C The Author(s). 2020 Open Access This article is licensed under a Creative Commons Attribution 4.0 International License, which permits use, sharing, adaptation, distribution and reproduction in any medium or format, as long as you give appropriate credit to the original author(s) and the source, provide a link to the Creative Commons licence, and indicate if changes were made. The images or other third party material in this article are included in the article's Creative Commons licence, unless indicated otherwise in a credit line to the material. If material is not included in the article's Creative Commons licence and your intended use is not permitted by statutory regulation or exceeds the permitted use, you will need to obtain permission directly from the copyright holder. To view a copy of this licence, visit http://creativecommons.org/licenses/by/4.0/ The Creative Commons Public Domain Dedication waiver (http://creativecommons.org/publicdomain/zero/1.0/) applies to the data made available in this article, unless otherwise stated in a credit line to the data. 
require relatively sophisticated equipment such as a body plethysmograph, or helium or nitrogen gas analyzers $[1,2]$. These measurements are usually done in specialized lung function laboratories. In recent years, TLC has also been measured using inspiratory and expiratory chest computed tomography [3].

Conversely, dynamic spirometry can be done at low cost. The procedure is simple and widely used, but does not measure TLC. Consequently, there is a need for a spirometric algorithm that identifies reduced TLC with high diagnostic accuracy. It has been suggested that low vital capacity in the absence of airflow limitation could be used as a proxy for true pulmonary restriction. The proxy restrictive spirometry pattern (RSP) has been defined as forced expiratory volume in $1 \mathrm{~s}\left(\mathrm{FEV}_{1}\right) /$ forced vital capacity $(\mathrm{FVC}) \geq 0.7$ and FVC $<80 \%$ predicted [4]. Alternative definitions, based on the lower limit of normal (LLN), are becoming more widely used, and the most common of these is to define RSP as $\mathrm{FEV}_{1} / \mathrm{FVC} \geq$ LLN and FVC $<$ LLN [2]. Slow vital capacity (SVC) is usually larger than the FVC [5]. Hence, it would also be of interest to define RSP using SVC instead of FVC.

We have identified five studies investigating RSP in relation to static lung volumes [1, 6-9]. All five studies were based on patients referred for spirometry and lung volume determination by plethysmograpy or gas dilution and selected controls. Generally, reduced TLC was defined as <LLN. The sensitivity of RSP ranged from 68 to $100 \%$ and the specificity from 61 to $93 \%$ depending chiefly on the chosen cut-off values for vital capacity.

Some general population studies report using RSP as a proxy for true pulmonary restriction [10-14]. However, the prevalence of true pulmonary restriction in these general population studies is unknown, as TLC was not measured. Further, the applied definitions of RSP varied with regard to whether results reflect measurements before or after bronchodilation and how the cut-off values were defined, for instance based on the LLN or on percentage of predicted normal values. There is a lack of data from general populations regarding whether RSP is a valid proxy for true pulmonary restriction. In other words, studies are lacking where persons in a random general population sample have been investigated with both dynamic spirometry and static lung volumes, TLC.

The RSP phenotype has been linked to diabetes, metabolic syndrome and increased mortality and RSP is probably capturing a different phenotype but overlapping group in relation to true pulmonary restriction, low TLC [2].

Hence, there is a need to perform a general population study examining the validity of the proxy RSP in identifying true pulmonary restriction. We have performed a validation study in a general population sample, for which we had access to measurements of TLC using body box, residual volume (RV), and dynamic spirometry before and after bronchodilation. Hence, we will have the possibility to validate RSP for indicating true pulmonary restriction.

\section{Material and methods}

Our data was from the pilot part of the Swedish CArdioPulmonary bioImage Study (SCAPIS Pilot), a Swedish general population-based study. For this initial pilot study, a randomly selected population sample of 2243 adults aged 50-64 years were invited to take part and 1111 agreed to participate [5, 15]. All persons answered an extensive respiratory questionnaire, including detailed items about smoking habits.

Dynamic spirometry, including $\mathrm{FEV}_{1}, \mathrm{FVC}$ and slow vital capacity (SVC) was performed before and $15 \mathrm{~min}$ after inhalation of $400 \mu \mathrm{g}$ of salbutamol using a nose clamp with the subject in a sitting position. All accepted exhalations had a duration of $>6 \mathrm{~s}$ and a plateau on the curve the last second of the exhalation. Static lung volumes, TLC and RV, were determined by body plethysmography based on two measurements recorded after bronchodilation. There were daily calibrations of pressure, volume and flow. All procedures were performed according to American Thoracic Society (ATS)/European Respiratory Society (ERS) standards [16]. There were daily volume controls of the spirometer. All betaagonist were withheld the day of the investigation. A Jaeger Master Screen pulmonary function (PFT) system (Vyaire, Mettawa, Illinois, US) was used for all measurements. Predicted values of $\mathrm{FEV}_{1}, \mathrm{FVC}$ and SVC were based on recently published local reference equations $[17,18]$. Predicted values for TLC and RV were based on published equations [19]. For analysis of TLC, we additionally developed a local reference equation for TLC based on the never-smokers in the present study population without any respiratory symptoms (wheeze, dyspnea, chronic bronchitis) and without self-reported heart diseases. All lung function values are generally expressed as percent predicted (\% predicted) or in relation to the LLN, using published locally equations $[17,18]$.

\section{Definitions}

True pulmonary restriction was defined as TLC $<$ LLN described as a $z$ score $<-1.645$ (i. e. a $z$ score below the fifth percentile), using both the published equations of Quanjer et al., TLC $<$ LLN $_{\text {QUANIER, and the local equa- }}$ tion TLC $<$ LLN $_{\text {GOTHENBURG, }}$, see "Statistics" [19].

Restrictive spirometric pattern (RSP) was in five different ways;

$\mathrm{RSP}_{\mathrm{LLN}}=\mathrm{FEV}_{1} / \mathrm{FVC} \geq \mathrm{LLN}$ and $\mathrm{FVC}<\mathrm{LLN}$ after bronchodilation 
$\mathrm{RSP}_{0.7}=\mathrm{FEV}_{1} / \mathrm{FVC} \geq 0.7$ and $\mathrm{FVC}<80 \%$ predicted after bronchodilation $[17,18]$.

$\mathrm{RSP}_{\text {PREDIL }}=\mathrm{FEV}_{1} / \mathrm{FVC} \geq \mathrm{LLN}$ and $\mathrm{FVC}<\mathrm{LLN}$ before bronchodilation $[17,18]$.

$\mathrm{RSP}_{\text {LLNSVC }}=\mathrm{FEV}_{1} / \mathrm{SVC} \geq \mathrm{LLN}$ and SVC $<\mathrm{LLN}$ after bronchodilation $[17,18]$.

$\mathrm{RSP}_{0.7 \mathrm{SVC}}=\mathrm{FEV}_{1} / \mathrm{SVC} \geq 0.7$ and $\mathrm{SVC}<80 \%$ predicted after bronchodilation $[17,18]$.

Asthma was defined as an affirmative answer to an item about physician-diagnosed asthma [20]. Dyspnea was defined as a modified Medical Research Council (mMRC) breathlessness score $\geq 2$ [21].

Smoking was categorized into current smokers, former smokers, and never-smokers. Former smokers were defined as those who had smoked for at least 1 year but who had not smoked during the past 12 months. In this analysis current smokers and former smokers were categorized as ever-smokers.

\section{Statistics}

All calculations were performed using SAS version 9.4 (SAS Institute, Cary, NC, USA). The local reference equation for TLC was computed by a linear regression model with height as a covariate, stratified by gender. The resulting equation for women was TLC=height $(\mathrm{cm})^{*} 0.085-8.71$, with residual standard deviation $(\mathrm{RSD})=0.56$. For men the equation was $\mathrm{TLC}=$ height $\left.(\mathrm{cm})^{*} 0.102-10.93\right)$, with $\mathrm{RSD}=0.83$.

Specificity, sensitivity, positive and negative predictive values (PPV, NPV), positive and negative likelihood ratios (LR+ and LR-) were calculated, and 95\% confidence intervals (CIs) were calculated using exact methods. Post-test probabilities of disease after positive and negative tests were assessed [22]. We calculated the percentiles of FVC, and sensitivity and specificity of $\mathrm{RSP}_{\mathrm{LLN}}$ using increasing percentiles of FVC were plotted. Factors associated with disconcordance between true pulmonary restriction and $R S P_{\text {LLN }}$ and $\mathrm{RSP}_{\text {LLNSVC }}$ were analyzed as

Table 1 Age, gender, smoking habits, symptoms and lung function values in 983 subjects according to different definitions of restrictive spirometry pattern (RSP) and true pulmonary restriction defined as TLC $<$ LLN

\begin{tabular}{|c|c|c|c|c|c|}
\hline & \multicolumn{3}{|c|}{ Restrictive spirometric pattern (RSP) } & \multicolumn{2}{|c|}{ True pulmonary restriction } \\
\hline & $\begin{array}{l}\mathrm{FEV}_{1} / \mathrm{FVC} \geq \mathrm{LLN} \text { and } \mathrm{FVC}< \\
\mathrm{LLN} \\
\left(\mathrm{RSP}_{\mathrm{LLN}}\right) \\
N=33(3.4 \%)\end{array}$ & $\begin{array}{l}\mathrm{FEV}_{1} / \mathrm{FVC} \geq 0.7 \text { and } \mathrm{FVC}< \\
80 \% \\
\left(\mathrm{RSP}_{0.7}\right) \\
N=31(3.2 \%)\end{array}$ & $\begin{array}{l}\mathrm{FEV}_{1} / \mathrm{FVC} \geq 0.7 \text { and } \mathrm{FVC}<80 \% \\
\text { predilation } \\
\left(\mathrm{RSP}_{\text {predil }}\right) \\
\mathrm{N}=33(3.4 \%)\end{array}$ & $\begin{array}{l}\mathrm{TLC}<\mathrm{LLN}_{5} \\
\text { (Quanjer) } \\
N=46(4.7 \%)\end{array}$ & $\begin{array}{l}\text { TLC }<\mathrm{LLN}_{5} \\
(\text { Gothenburg) } \\
N=53(5.4 \%)\end{array}$ \\
\hline $\begin{array}{l}\text { Males } \\
n=500(50.9 \%)\end{array}$ & $n=19(57.6 \%)$ & $n=17(54.8 \%)$ & $n=18(54.5 \%)$ & $\begin{array}{l}n=39 \\
(84.8 \%)\end{array}$ & $\begin{array}{l}n=28 \\
(68.3 \%)\end{array}$ \\
\hline BMI $\left(\mathrm{kg} / \mathrm{m}^{2}\right)$ & $29.3(6.1)$ & $29.8(6.5)$ & $29.2(5.7)$ & $28.8(5.2)$ & $28.6(5.5)$ \\
\hline Age (yrs) & $57.0(4.2)$ & $57.9(4.2)$ & $56.8(4.47)$ & $57.8(4.5)$ & $56.9(4.4)$ \\
\hline $\begin{array}{l}\text { Ever-smokers } \\
n=570(58.0 \%)\end{array}$ & $n=21(63.6 \%)$ & $n=17(54.8 \%)$ & $n=20(60.6 \%)$ & $\begin{array}{l}n=25 \\
(50.0 \%)\end{array}$ & $\begin{array}{l}n=21 \\
(51.2 \%)\end{array}$ \\
\hline $\begin{array}{l}\text { Never-smokers } \\
n=417(42.4 \%)\end{array}$ & $n=12(36.4 \%)$ & $n=14(45.2 \%)$ & $n=13(39.4 \%)$ & $\begin{array}{l}n=25 \\
(50.0 \%)\end{array}$ & $\begin{array}{l}n=20 \\
(48.8 \%)\end{array}$ \\
\hline $\begin{array}{l}\text { FEV }_{1} \\
\text { (\% pred) }\end{array}$ & $76.1(8.7)$ & $75.7(8.8)$ & $78.8(8.2)$ & $82.9(17.1)$ & $84.4(18.6)$ \\
\hline $\begin{array}{l}\text { FVC } \\
\text { (\% pred) }\end{array}$ & $74.0(6.6)$ & $73.3(6.3)$ & $77.6(7.3)$ & $80.5(17.7)$ & $82.8(19.2)$ \\
\hline $\begin{array}{l}\text { TLC QUANJER } \\
\text { (\% pred) }\end{array}$ & $90.3(7.7)$ & $90.7(8.2)$ & $89.6(7.4)$ & $74.6(8.5)$ & $73.0(8.6)$ \\
\hline $\begin{array}{l}\text { TLC } C_{\text {GOTHENBURG }} \\
\text { (\% pred) }\end{array}$ & $84.9(7.0)$ & $85.9(7.8)$ & $84.1(6.5)$ & $77.5(5.6)$ & $77.8(5.3)$ \\
\hline $\begin{array}{l}\text { RV } \\
\text { (\% pred) }\end{array}$ & $99.2(29.8)$ & $99.9(30.9)$ & $100.4(29.4)$ & $84.5(26.0)$ & $82.6(27.4)$ \\
\hline $\begin{array}{l}\text { Asthma } \\
n=93(9.5 \%)\end{array}$ & $N=3(9.1 \%)$ & $n=2(6.5 \%)$ & $n=3(9.1 \%)$ & $n=4(8.0 \%)$ & $n=4(9.8 \%)$ \\
\hline $\begin{array}{l}M R C \geq 2 \\
n=51(5.2 \%)\end{array}$ & $N=5(15.2 \%)$ & $n=5(16.1 \%)$ & $n=5(15.2 \%)$ & $n=4(8.0 \%)$ & $n=5(12.2 \%)$ \\
\hline $\begin{array}{l}\text { Diabetes } \\
N=165(16.7 \%)\end{array}$ & $N=8(24.2 \%)$ & $N=7(22.6 \%)$ & $N=7(21.2 \%)$ & $\begin{array}{l}N=11 \\
(23.9 \%)\end{array}$ & $\begin{array}{l}N=11 \\
(20.8 \%)\end{array}$ \\
\hline $\begin{array}{l}\text { Myocardial } \\
\text { infarction } \\
N=27(2.8 \%)\end{array}$ & $N=1(3.1 \%)$ & $N=3(10 \%)$ & $N=1(3.0 \%)$ & $N=3(6.7 \%)$ & $N=3(5.7 \%)$ \\
\hline
\end{tabular}

Definition of abbreviations: BMI Body mass index, FEV 1 Forced expiratory volume in one second, FVC Forced vital capacity, LLN Lower limit of normal, TLC Total lung capacity, RV Residual volume, MRC Medical Research Council 
odds ratios (OR), using multiple logistic regression. The variables age, body mass index, gender, smoking habits and RV were a priori selected as potentially associated with disconcordance.

\section{Results}

Of the 1111 subjects, 128 were excluded because of incomplete data on smoking and dynamic spirometry or missing TLC measurements, resulting in a final study population of 983 subjects. Descriptive data on age, gender, smoking, lung function, and prevalence of asthma and dyspnea is shown in Table 1. The prevalence of true pulmonary restriction, TLC $<\mathrm{LLN}_{\text {QUANJER, }}$ was $4.7 \%$ $(n=46)$, and when using our local equation, the prevalence of TLC $<\operatorname{LLN}_{\mathrm{GOTHENBURG}}$ was $5.4 \%(n=53)$. The prevalence of $\mathrm{RSP}_{\mathrm{LLN}}, \mathrm{RSP}_{0.7}$, and RSP PREDIL was, $3.4 \%$ $(n=33), 3.2 \%(n=31)$, and $3.4 \%(n=23)$, respectively. When applying SVC, the prevalence of RSP $\mathrm{LLNSVC}_{\text {and }}$ $\mathrm{RSP}_{0.7 \mathrm{SVC}}$ was $2.1 \%(n=21)$ and $1.8 \%(n=18)$, respectively (Online Supplement Table S1).

The specificity, sensitivity, NPV and PPV, positive and negative likelihood ratio of $\mathrm{RSP}_{0.7}, \mathrm{RSP}_{\mathrm{LLN}}$ and $\mathrm{RSP}_{\mathrm{PRE}}$ DIL in relation to true pulmonary restriction, defined either according to Quanjer et al. or based the Gothenburg equation, are shown in Table 2. When applying the Quanjer equation, the sensitivity of identifying TLC $<$ LLN $_{\text {QUANJER }}$, was about 0.30 for all definitions of RSP. The highest sensitivity, 0.33 , was in relation to RSP $_{\text {LLN }}$. The specificity was 0.98 for all definitions of RSP. All the RSP definitions has a high positive likelihood ratio, 17 to 24 . With a pretest probability (prevalence) of true pulmonary restriction of $5.4 \%$, a LR+ around 21 indicates a $50 \%$ post-test probability of true pulmonary restriction if presence of RSP. The negative likelihood ratios ranged from 0.67 to 0.71 . A negative likelihood ratio around 0.70 means that there is a $4 \%$ post-test probability of true pulmonary restriction if there is no RSP. When applying the Gothenburg TLC equations to calculate predicted values the results were quite similar as compared to the Quanjer equation (Table 2). The sensitivity of identifying TLC $<$ $\mathrm{LLN}_{\mathrm{GOTHENBURG}}$ ranged from 0.32 to 0.36 . A plot of increasing percentiles of FVC in the definition of RSP $\mathrm{LLN}_{\mathrm{N}}$ is shown in Fig. 1. Increasing the FVC from the 10th percentile to the 20th percentile increased the sensitivity from 0.55 to 0.80 , with moderately decreased specificity. The max sensitivity and specificity was around 25 th percentile of FVC.

When applying SVC, the specificity, sensitivity, NPV and PPV, positive and negative likelihood ratio of $\mathrm{RSP}_{\mathrm{LLNSVC}}$ and $\mathrm{RSP}_{0.7 \mathrm{SVC}}$ in relation to true pulmonary restriction, defined either according to Quanjer et al. or based the Gothenburg equation, are shown in Table 3. Using SVC instead of FVC resulted in lower sensitivity
Table 2 Validity of restrictive spirometric pattern (RSP) in relation to true pulmonary restriction

\begin{tabular}{|c|c|c|c|c|}
\hline \multirow{3}{*}{$\begin{array}{l}\text { Restrictive } \\
\text { spirometric } \\
\text { pattern } \\
\text { (RSP) }\end{array}$} & \multicolumn{4}{|c|}{ True pulmonary restriction } \\
\hline & \multicolumn{2}{|c|}{$\begin{array}{l}\mathrm{TLC}<\mathrm{LLN}_{5} \\
\text { (Quanjer) } \\
(n=46)\end{array}$} & \multicolumn{2}{|c|}{$\begin{array}{l}\mathrm{TLC}<\mathrm{LLN}_{5} \text { (Gothenburg) } \\
(n=53)\end{array}$} \\
\hline & Value & $95 \% \mathrm{Cl}$ & Value & $95 \% \mathrm{Cl}$ \\
\hline \multicolumn{5}{|l|}{$\operatorname{RSP}_{\text {LLN }}(n=33)$} \\
\hline Sensitivity & 0.33 & $0.20-0.48$ & 0.34 & $0.20-0.46$ \\
\hline Specificity & 0.98 & $0.97-0.99$ & 0.98 & $0.97-0.99$ \\
\hline PPV & 0.45 & $0.28-0.64$ & 0.55 & $0.36-0.72$ \\
\hline NPV & 0.97 & $0.97-0.95$ & 0.96 & $0.95-0.97$ \\
\hline LR+ & 17.0 & $9.2-31.5$ & 21.1 & $11.3-39.4$ \\
\hline LR- & 0.69 & $0.56-0.84$ & 0.67 & $0.55-0.81$ \\
\hline \multicolumn{5}{|l|}{$\operatorname{RSP}_{0.7}(n=31)$} \\
\hline Sensitivity & 0.30 & $0.18-0.46$ & 0.32 & $0.28-0.60$ \\
\hline Specificity & 0.98 & $0.98-0.97$ & 0.98 & $0.97-0.99$ \\
\hline PPV & 0.45 & $0.27-0.64$ & 0.55 & $0.36-0.73$ \\
\hline NPV & 0.97 & $0.95-0.98$ & 0.96 & $0.95-0.97$ \\
\hline LR+ & 16.8 & $8.8-31.9$ & 21.3 & $11.1-40.9$ \\
\hline LR- & 0.71 & $0.59-0.86$ & 0.69 & $0.57-0.83$ \\
\hline \multicolumn{5}{|c|}{$\operatorname{RSP}_{\text {PREDIL }}(n=33)$} \\
\hline Sensitivity & 0.30 & $0.18-0.46$ & 0.36 & $0.23-0.50$ \\
\hline Specificity & 0.98 & $0.97-0.99$ & 0.98 & $0.97-0.99$ \\
\hline PPV & 0.42 & $0.25-0.61$ & 0.58 & $0.39-0.75$ \\
\hline NPV & 0.97 & $0.95-0.98$ & 0.96 & $0.95-0.98$ \\
\hline LR+ & 15.0 & $8.1-28.0$ & 23.8 & $12.7-44.9$ \\
\hline LR- & 0.71 & $0.59-0.86$ & 0.65 & $0.53-0.80$ \\
\hline
\end{tabular}

Definition of abbreviations: LLN Lower limit of normal; total lung capacity, PPV Positive predictive value, NPV Negative predictive value, $L R+$ Positive likelihood ratio, $L R$ - Negative likelihood ratio

and higher specificity, with no obvious differences between whether true pulmonary restriction was defined based on the Quanjer or the Gothenburg equation.

Body mass index was positively associated with discordance between RSP and true pulmonary restriction (OR 1.10, 95\% CI 1.03-1.17) and residual volume was negatively associated (OR 0.96, 95\% CI 0.94-0.97) (Table 4).

\section{Discussion}

The main result of the present study is that the sensitivity of RSP was fairly low in relation to true pulmonary restriction, whereas the specificity and NPV were high. The validity, sensitivity, and specificity were similar, regardless of which definition of RSP that was used. Finally, there was no difference between the pre- and post-bronchodilation results. Hence, we confirm previous results from referred-based populations, that RSP is 


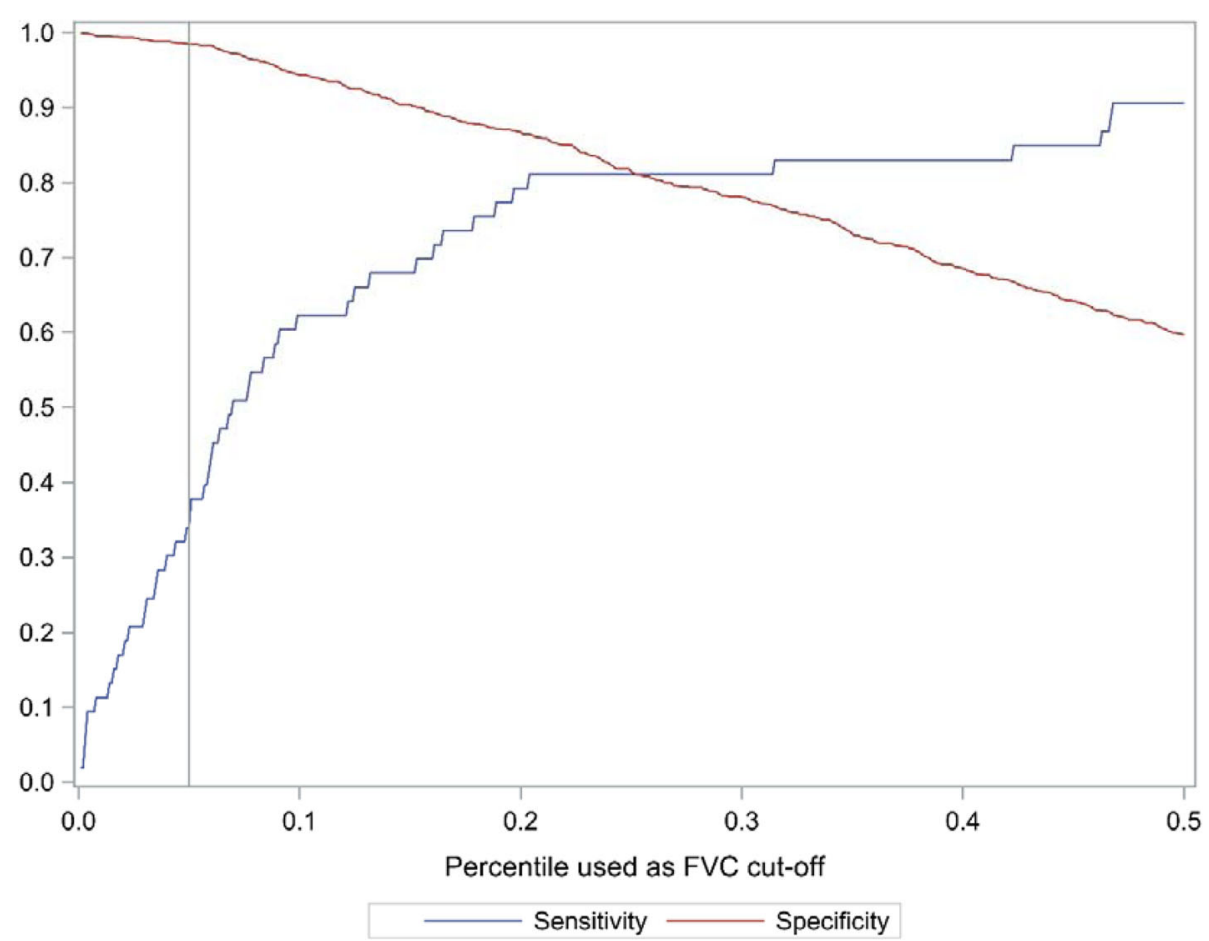

Fig. 1 Sensitivity and specificity of restrictive spirometric pattern (RSP $\operatorname{LLN}_{\text {) }}$ ) defined as FEV $1 / F V C \geq L L N$ and FVC $<$ LLN after bronchodilation using locally published Eqs. (17-18) in relation to true pulmonary restriction defined as TLC $<$ LLN applying increasing percentiles (cut-off values) of FVC

Table 3 Validity of restrictive spirometric pattern using slow vital capacity (RSP LLnsve and RSP $_{0.75 v C}$ ) in relation to true pulmonary restriction

\begin{tabular}{|c|c|c|c|c|}
\hline \multirow{3}{*}{$\begin{array}{l}\text { Restrictive } \\
\text { spirometric } \\
\text { pattern } \\
\text { (RSP) }\end{array}$} & \multicolumn{4}{|c|}{ True pulmonary restriction } \\
\hline & \multicolumn{2}{|c|}{$\begin{array}{l}\mathrm{TLC}<\mathrm{LLN}_{5} \\
\text { (Quanjer) } \\
\text { (n=46) }\end{array}$} & \multicolumn{2}{|c|}{$\begin{array}{l}\mathrm{TLC}<\mathrm{LLN}_{5} \\
\text { (Gothenburg) } \\
(n=53)\end{array}$} \\
\hline & Value & $95 \% \mathrm{Cl}$ & Value & $95 \% \mathrm{Cl}$ \\
\hline \multicolumn{5}{|c|}{$\operatorname{RSP}_{\text {LLNSVC }}(n=33)$} \\
\hline Sensitivity & 0.24 & $0.13-0.39$ & 0.26 & $0.15-0.40$ \\
\hline Specificity & 0.99 & $0.98-0.99$ & 0.99 & $0.98-1.00$ \\
\hline PPV & 0.52 & $0.30-0.74$ & 0.67 & $0.43-0.85$ \\
\hline NPV & 0.96 & $0.95-0.97$ & 0.96 & $0.94-0.97$ \\
\hline $\mathrm{LR}+$ & 22.4 & $9.2-31.5$ & 35.1 & $14.8-83.3$ \\
\hline LR- & 0.77 & $0.56-0.84$ & 0.74 & $0.63-0.87$ \\
\hline \multicolumn{5}{|c|}{$\operatorname{RSP}_{0.7 D S V C}(n=31)$} \\
\hline Sensitivity & 0.22 & $0.11-0.36$ & 0.21 & $0.11-0.34$ \\
\hline Specificity & 0.99 & $0.98-1.00$ & 0.99 & $0.98-1.00$ \\
\hline PPV & 0.56 & $0.31-0.78$ & 0.61 & $0.36-0.83$ \\
\hline NPV & 0.96 & $0.95-0.97$ & 0.96 & $0.94-0.97$ \\
\hline $\mathrm{LR}+$ & 25.4 & $10.6-61.5$ & 27.6 & $11.1-68.3$ \\
\hline LR- & 0.79 & $0.68-0.92$ & 0.80 & $0.70-0.92$ \\
\hline
\end{tabular}

Definition of abbreviations: LLN Lower limit of normal; total lung capacity; PPV Positive predictive value, NPV Negative predictive value, $L R+$ Positive likelihood ratio, $L R$ - Negative likelihood ratio, SVC Slow vital capacity relevant for ruling out true pulmonary restriction, and RSP has low validity in identifying true pulmonary restriction.

This is, to the best of our knowledge, the first study of a general population sample, although in a narrow age interval, sample validating RSP in relation to true pulmonary restriction, based on measurements of TLC by body plethysmography. Our results confirm results from previous clinical studies indicating a high NPV for RSP used as a proxy. This means that spirometry with no sign of RSP makes it highly unlikely that the person has

Table 4 Logistic regression model of factors associated with disconcordance regarding true pulmonary restriction and restrictive spirometric pattern (RSP). All included co-variates are presented in the table

\begin{tabular}{lll}
\hline & \multicolumn{2}{l}{ Restrictive spirometric pattern (RSP) } \\
\cline { 2 - 3 } Co-variate & $\begin{array}{l}\text { RSP } \\
\text { Odds }\end{array}$ & $\begin{array}{l}\text { RSP } \\
\text { LLNSVC }\end{array}$ \\
\hline Age (yrs) & $1.02(0.95-1.09)$ & $1.04(0.97-1.12)$ \\
Body mass index (kg/m²) & $1.10(1.03-1.17)$ & $1.10(1.02-1.18)$ \\
Women vs. men & $0.58(0.31-1.06)$ & $0.43(0.22-0.84)$ \\
Eversmoking (Yes/No) & $0.85(0.47-1.55)$ & $0.62(0.33-1.17)$ \\
Residual volume (proc pred) & $0.96(0.94-0.97)$ & $0.94(0.93-0.96)$ \\
\hline $\begin{array}{l}\text { Definition of abbreviations: LLN Lower limit of normal, SVC Slow vital capacity, } \\
\text { Cl Confidence interval }\end{array}$
\end{tabular}


true pulmonary restriction. When the prevalence of the true condition is low $(<5 \%)$, as in this case, the NPV rather accurately reflects that a negative test indicates no abnormality [23]. This conclusion is also supported by the low LR-. A high NPV (and low LR-) is especially valid in clinical situations where we have to consider whether to investigate a patient with lung volumes. In a clinical population, compared to a population study, the prevalence of true pulmonary restriction is probably higher. Hence, in the clinical situations the RSP may be more valid as a proxy for true pulmonary restriction. Still, the present results confirm earlier results that the proxy RSP could be used for ruling out true pulmonary restriction.

Even if the specificity was 0.98 , this level of specificity of a test will generate a substantial number of false positives when applied in a general population study when the true condition, true pulmonary restriction, has a low prevalence. This will lead to falsely decreased risk estimates because of misclassification of the disease [24]. The conclusion from the present study is that RSP is a proxy for true pulmonary restriction with low validity. We made additional analysis using SVC instead of FVC. Not surprisingly, the prevalence of RSP decreased, the sensitivity decreased and the specificity went up to 0.99 , further supporting previous conclusions.

We found that high BMI and low residual volume were associated with this disconcordance. There was also an association with disconcordance and male gender, although with borderline significance. The results were more obvious when using RSP $_{\text {LLNSVC }}$ instead of RSP ${ }_{\text {LLN }}$. In clinical practice that means that overweight men may be at risk for disconcordant results. The material was too small to differentiate whether the disconcordance was dependent on true pulmonary restriction or on RSP.

The RSP phenotype has been linked to diabetes, metabolic syndrome and increased mortality [2]. The prevalence of RSP has mostly been below $10 \%$, but in low and middle income countries prevalence figures between 25 and $69 \%$ have been reported. Some studies also report that RSP is more prevalent in older strata of the population [14, 25]. In a random population from Northern Sweden, the prevalence of RSP (after bronchodilation) was $5.4 \%$ in the age group 40 to 60 years [14]. Our study indicated a slightly lower prevalence, around $3 \%$.

We used a published reference equation to estimate the predicted values of TLC [19]. In accordance with recommendations from the ATS/ERS Task Force, we also developed a local reference equation based on 354 healthy never-smokers [26]. These equations were developed using only height as a covariate, stratified for gender, applying the model described by Quanjer et al. [19]. The results were fairly similar, although the sensitivity was somewhat higher using the Gothenburg equations. The local equation did not add much to the results other than indicating that the published equation was suitable for our population. However, it has to be added that the present equations are not satisfactory as they are based on small populations. An equation for TLC and RV based on larger populations are highly warranted.

The main weakness of the present study is the small study sample. We have outlined $95 \%$ confidence interval around our estimates to be able to judge the reliability of our results. Another limitation is the narrow age interval 50-64 years, making the conclusions valid for this age group only. Selection bias may be a problem, as the participation rate was around $50 \%$. In the current population chronic obstructive pulmonary disease and cardiovascular disease seem to have increased the participation, but we believe this has only marginally affected the validity of the estimates [27].

\section{Conclusion}

RSP has low validity for identifying true pulmonary restriction. We do not recommend using RSP in general population studies as a proxy for true pulmonary restriction. Our results support previous observations that RSP is useful for ruling out true pulmonary restriction.

\section{Supplementary information}

Supplementary information accompanies this paper at https://doi.org/10. 1186/s12890-020-1096-z.

Additional file 1: Table S1. Age, gender, smoking habits, symptoms and lung function values in 983 subjects according to different definitions of restrictive spirometry pattern (RSP) based on slow vital capacity.

\section{Abbreviations}

$\mathrm{Cl}$ : Confidence interval; $\mathrm{FEV}_{1}$ : Forced expiratory volume in one second; FVC: Forced vital capacity; LLN: Lower limit of normal; LR: Likelihood ratio; OR: Odds ratio; PREDIL: Prebronchodilation; RSD: Residual standard deviation; RSP: Restrictive spirometric pattern; RV: Residual volume; SCAPIS: Swedish CArdioPulmonary biolmage Study; SVC: Slow vital capacity; TLC: Total lung capacity

Authors' contributions

K.T., J.B., A.M., A-C.O., G.B. and B.B. jointly designed the study. G.B. and K.T. collected the data. K.T. and B.B. performed the statistical analyses. K.T. drafted the manuscript and all authors contributed to the final manuscript. The authors read and approved the final manuscript.

\section{Funding}

This study was supported by the Swedish Heart and Lung Foundation, the Knut and Alice Wallenberg Foundation, the Swedish Research Council (VR), VINNOVA, the Swedish Council for Working Life, Health, and Welfare (FORTE) and strategic grants from ALF/LUA in Western Sweden and from the Sahlgrenska Academy at University of Gothenburg. The funding agencies had no role in the study design; collection, analysis, or interpretation of data; drafting of the manuscript; or decision to submit for publication. Open access funding provided by University of Gothenburg.

Availability of data and materials

The data is available upon request to the corresponding author. All analyses requires a permission from a Swedish ethical committee. A detailed description of the database can be found at www.scapis.org. 


\section{Ethics approval and consent to participate}

The study was approved by the Regional Committee of Ethics in Umeå, (2010/228-31), and all included subjects gave their written consent to participate in the study.

\section{Consent for publication}

Not applicable.

\section{Competing interests}

All authors have completed the Unified Competing Interest form att www. icmje/coi_disclosure.pdf and they do not have any conflict of interest to report

\section{Author details}

'Occupational and Environmental Medicine, School of Public Health and Community Medicine, Sahlgrenska Academy, University of Gothenburg, Box 414, S-405 30 Gothenburg, Sweden. ${ }^{2}$ Department of Occupational and Environmental Medicine, Sahlgrenska University Hospital, Gothenburg, Sweden. ${ }^{3}$ Department of Medical Sciences, Uppsala University, Uppsala Sweden. ${ }^{4}$ Department of Molecular and Clinical Medicine, Institute of Medicine, Sahlgrenska Academy, University of Gothenburg, Gothenburg, Sweden. ${ }^{5}$ Department of Medicine/Lung Medicine, Sahlgrenska Academy, University of Gothenburg, Gothenburg, Sweden.

Received: 1 October 2019 Accepted: 19 February 2020

Published online: 27 February 2020

\section{References}

1. Aaron SD, Dales RE, Cardinal P. How accurate is spirometry at predicting restrictive pulmonary impairment? Chest. 1999;115:869-73.

2. Godfrey MS, Jankowich MD. The vital capacity is vital. Epidemiological and clinical significance of the restrictive spirometry pattern. Chest. 2016;149: 238-51

3. Wan ES, Castaldi PJ, Cho MH, Hokanson J, Regan EA, Make BJ, et al. COPDGene Investigators. Epidemiology, genetics, and subtyping of preserved ratio spirometry (PRISm) in the COPDGene Study. Respir Res. 2014;15:89.

4. Crapo R. Pulmonary-function testing. N Engl J Med. 1994;331:25-30.

5. Torén K, Olin A-C, Lindberg A, Vikgren J, Schiöler L, Brandberg J, et al. Vital capacity and COPD: the Swedish CArdioPulmonary Biolmage study (SCAPIS). Int J COPD. 2016;11:927-3.

6. Gilbert R, Auchincloss JH. What is a "restrictive" defect? Arch Intern Med. 1986;146:1779-81.

7. Glady CA, Aaron SD, Lunau M, Clinch J, Dales RE. A spirometry-based algorithm to direct lung function testing in the pulmonary function laboratory. Chest. 2003:123:1939-46.

8. Swanney MP, Backertt LE, Frampton CM, Wallace LA, Jensen RL, Crapo RO. Validity of the American Thoracic Society and other spirometric algoritms using FVC and forced expiratory volume at $6 \mathrm{~s}$ for predicting a reduced total lung capacity. Chest. 2004;126:1861-6.

9. Venkateshiah SB, loachimescu OC, McCarthy K, Stoller JK. The utility of spirometry in diagnosing pulmonary restriction. Lung. 2008;186:19-25.

10. Mannino DM, Ford ES, Redd SC. Obstructive and restrictive lung disease and functional limitation: data from the third National Health and nutrition Examonation. J Intern Med. 2003;254:540-7.

11. Guerra S, Sherill DL, Venker C, Ceccato CM, Halonen M, Martinez FD. Morbidity and mortality associated with the restrictive spirometric pattern: a longitudinal study. Thorax. 2010;65:499-504.

12. Mannino DM, McBurnie MA, Tan W, Kocabas A, Anto J, Wollmer WM, et al. Restricted spirometry in the burden of lung disease study. Int I Tuberc Lung Dis. 2012;16:1405-11.

13. Odo NU, Mandel JH, Perlman DM, Alexander BH, Scanlon PD. Estimates of restrictive ventilatory defect in the mining industry. Considerations for epidemiological investigations: A cross-sectional study BMJ Open. 2013;3: e002561.

14. Backman H, Eriksson B, Hedman L, Stridsman C, Jansson S-A, Sovijärvi A, et al. Restrictive spirometric pattern in the general adult population: methods of defining the condition and consequences on prevalence. Respir Med. 2016;120:116-23.
15. Bergström G, Berglund G, Blomberg A, Brandberg J, Engström G, Engvall J, et al. The Swedish CArdioPulmonary Biolmage study (SCAPIS): objectives and design. J Int Med J Int Med. 2015;278:645-59.

16. Miller MR, Hankinson J, Brusasco V, Burgos F, Casaburi R, Coates A, et al. Standardisation of spirometry. Eur Respir J. 2005;26:319-38.

17. Brisman J, Kim J-L, Olin A-C, Torén K, Bake B. Spirometric reference equations in adults. Clin Physiol Funct Imag. 2017;37:640-5.

18. Brisman J, Kim J-L, Olin A-C, Torén K, Bake B. A physiologically based model for spirometric equations in adults. Clin Physiol Funct Imaging. 2016;36:77-84.

19. Quanjer PH, Tammeling GJ, Cotes JE, Pedersen OF, Peslin R, Yemault JC. Lung volumes and ventilatory flows. Report working party "standardization of lung function tests". Eur Respir J. 1993;6(Suppl 16):5-40.

20. Torén K, Palmqvist M, Löwhagen O, Balder B, Tunsäter A. Accuracy of selfreported year of asthma-onset. J Clin Epidemiol. 2006;59:90-3.

21. Bestall JC, Paul EA, Garrod R, Garnham R, Jones PW, Wedzicha JA. Usefulness of the Medical Research Council (MRC) dyspnoea scale as measure of disability in patients with chronic obstructive pulmonary disease. Thorax. 1999;54:581-6.

22. van Stralen KJ, Stel VS, Reitsma JB, Dekker FW, Zoccali C, Jager KJ. Diagnostic methods I: sensitivity, specificity, and other measures of accuracy. Kidney Int. 2009;75:1257-63.

23. Altman DG. Practical statistics for medical research. Boca Raton: Chapman\&Hall/CRC; 1999.

24. Copeland KT, Checkoway H, McMichael AJ, Holbrook RH. Bias due to misclassification in the estimation of relative risk. Am J Epidemiol. 1977;105: 488-95.

25. Feng L, Lim ML, Collinson S, Ng TP. Pulmonary function and cognitive decline in an older Chinese population in Singapore. COPD. 2012;9:555-62.

26. Pellegrino R, Viegi G, Brusasco V, Crapo RO, Burgos F, Casaburi R, et al. Interpretative strategies for lung function tests. Eur Respir J. 2005;26:948-68.

27. Björk J, Strömberg U, Rosengren A, Torén K, Fagerberg B, Grimby-Ekman A, et al. Predicting participation in the population-based Swedish cardiopulmonary bio-image study (SCAPIS) using register data. Scan J Publ Health. 2017:45(Suppl 17):45-9.

\section{Publisher's Note}

Springer Nature remains neutral with regard to jurisdictional claims in published maps and institutional affiliations.

Ready to submit your research? Choose BMC and benefit from:

- fast, convenient online submission

- thorough peer review by experienced researchers in your field

- rapid publication on acceptance

- support for research data, including large and complex data types

- gold Open Access which fosters wider collaboration and increased citations

- maximum visibility for your research: over $100 \mathrm{M}$ website views per year

At $\mathrm{BMC}$, research is always in progress.

Learn more biomedcentral.com/submissions 